\title{
Clinical Study of Rape against Females at the Yaoundé Gyneco-Obstetric and Pediatric Hospital, Cameroun
}

\author{
Pascal Foumane ${ }^{*}$, Julius Sama Dohbit ${ }^{1}$, Francisca Monebenimp1, Bruno Natolga ${ }^{2}$, \\ Esther Ngo Um Meka3 ${ }^{3}$ Emile Telesphore Mboudou ${ }^{1}$ \\ ${ }^{1}$ Faculty of Medicine and Biomedical Sciences, University of Yaoundé 1 Cameroon, Yaoundé, Cameroon \\ ${ }^{2}$ High Institute of Health Sciences, Université des Montagnes, Bangangté, Cameroon \\ ${ }^{3}$ Yaoundé Gyneco-Obstetric and Pediatric Hospital, Yaoundé, Cameroon \\ Email: *pfoumane2004@yahoo.fr
}

Received 12 January 2014; received 12 February 2014; accepted 20 February 2014

Copyright (C) 2014 by authors and Scientific Research Publishing Inc.

This work is licensed under the Creative Commons Attribution International License (CC BY). http://creativecommons.org/licenses/by/4.0/

(c) (i) Open Access

\begin{abstract}
Objective: To describe the clinical and therapeutic aspects of rape against females in a tertiary level hospital, Yaoundé, Cameroon. Methods: This was a cross-sectional study with a retrolective collection of data, concerning the female patients with a clinical diagnosis of rape received from January $1^{\text {st }} 2008$ to December $31^{\text {st }} 2012$. Results: Rape was confirmed at physical examination in 131 cases. The rape victim survivals were mostly aged less than 20 years $(85 / 131 ; 64.9 \%)$, unmarried $(127 / 131 ; 97.0 \%)$, with no income $(95 / 131 ; 72.5 \%)$ and had no university education level $(110 / 131 ; 83.9 \%)$. The aggression commonly took place during the night $(68 / 131 ; 51.9 \%)$, at the victim's or aggressor's home $(70 / 131 ; 53.4 \%)$, with physical constraint $(73 / 131 ; 55.8 \%)$, by an unknown aggressor $(88 / 131 ; 67.2 \%)$. A vaginal penetration was reported by $97.0 \%$ of the victims $(127 / 131)$ while $12.2 \%$ of them $(16 / 122)$ had an anal ingress. Condom usage was uncommon during rape $(3 / 131 ; 2.3 \%)$. Vulvar and vaginal lesions were encountered in $32.8 \%$ of the cases (43/131). Only $27.5 \%(36 / 131)$ of the victims were prescribed an emergency contraception, while antiretroviral prophylaxis was administered to $46.6 \%(61 / 131)$ of them. Conclusion: These data might be useful for prevention of rape. The clinical management of survival victims of rape needs to be improved.
\end{abstract}

\section{Keywords}

Rape, Victims, Genital Lesions, Vaginal and Anal Penetration, HIV Prophylaxis, Cameroon

\footnotetext{
${ }^{*}$ Corresponding author.
} 


\section{Introduction}

Sexual assault has previously been reported in Cameroon by several authors, most of them being focused on child sexual abuse [1]-[4]. In 1992, Koki Ndombo et al. published a series of 17 cases of rape in children and found a majority of hymeneal and perineal tears among them [1]. Later on, Menick et al. reported a larger series of 104 cases of sexual abuse in Cameroon, rape being encountered in $97.1 \%$ of the cases [2]. The same authors also found a 15.9\% frequency of sexual abuse among 1668 responders from ten secondary schools located in Yaoundé [3]. Also, an HIV prevalence as high as 37.5\% has been reported in Cameroonian sexually abused children [4] [5]. Apart from the publication of Koki Ndombo et al. in children in 1992 [1], less is still known on the clinical aspects of sexual abuse in Cameroon. The objective of this study was therefore to describe the clinical and therapeutic aspects of rape against females at the Yaoundé Gyneco-Obstetric and Pediatric Hospital, Cameroon. The results of the present study would provide useful data for decision making in order to improve the clinical and therapeutic care of victims of rape in our setting.

\section{Materials and Methods}

This was a cross-sectional study with a retrolective collection of data carried out at the Yaoundé Gyneco-Obstetric and Pediatric Hospital, Cameroon, on female patients with a clinical diagnosis of rape received from January $1^{\text {st }}$ 2008 to December $31^{\text {st }}$ 2012. Authorizations were obtained from the National Ethical Committee and the authorities of the Yaoundé Gyneco-Obstetric and Pediatric Hospital. The information was retrieved from the files of patients and a pretested form filled by an investigator. Studied variables were: age, marital status, education level, socioeconomic level, reason for consultation, time and place of the assault, type of constraint, type of ingress, condom usage, clinical lesions, relationship with the abuser, HIV testing, treatment and prophylaxis. Data were analyzed using Excel 2007 software.

\section{Results}

During the study period, 131 cases of rape were confirmed at physical examination, giving a frequency of $26.2 \%$ of confirmed rape per year. The mean age of raped victims was 16.6 years and 28 victims (28/131; 21.4\%) were aged less than 10 years.

They were mostly aged less than 20 years (85/131; 64.9\%), unmarried (127/131; 97.0\%), with no regular income (95/131; 72.5\%). One quarter of the raped victims were illiterate (35/131; 26.7\%), while 19.8\% (26/131) of them had a primary school education level and 37.4\% (49/131) a secondary school education level (Table 1).

Table 1. Sociodemographic characteristics of the victims of rape $(n=131)$.

\begin{tabular}{cc|}
\hline Variable & $\mathrm{n}(\%)$ \\
\hline Age groups (years) & \\
$<10$ & $28(21.4)$ \\
{$[10-20]$} & $57(43.5)$ \\
{$[20-30]$} & $39(29.8)$ \\
{$[30-40]$} & $6(4.6)$ \\
$\geq 40$ & $1(0.7)$ \\
Marital status & $127(97.0)$ \\
Unmarried & $3(2.3)$ \\
Married & \\
Education level & $35(26.7)$ \\
None & $26(19.8)$ \\
Primary school & $49(37.4)$ \\
Secondary school & $21(16.1)$ \\
University & \\
Socioeconomic level & $95(72.5)$ \\
No income & $36(27.5)$ \\
Regular income &
\end{tabular}


As shown in Table 2, the victims mainly consulted for sexual assault (118/131; 90.1\%), and the aggression commonly took place during the night (68/131; 51.9\%), at the victim's or the rapist's home (70/131; 53.4\%), with physical constraint $(73 / 131 ; 55.8 \%)$. A vaginal penetration was reported by $97.0 \%$ of the victims $(127 / 131)$ while $12.2 \%$ of them (16/122) had an anal ingress. Condom usage was uncommon during rape (3/131; 2.3\%). Lesions encountered were vulvo-vaginal in 29 cases $(29 / 131 ; 22.1 \%)$, only vaginal in nine cases (9/131; 6.9\%), only vulvar in 5 cases $(5 / 131 ; 3.8 \%)$ and anal in one case $(1 / 131 ; 0.8 \%)$.

Table 2. Clinical characteristics of the assault $(n=131)$.

\begin{tabular}{|c|c|}
\hline Variable & n (\%) \\
\hline \multicolumn{2}{|l|}{ Reason for consultation } \\
\hline Sexual assault & $118(90.1)$ \\
\hline Bleeding & $7(5.3)$ \\
\hline Others & $6(4.6)$ \\
\hline \multicolumn{2}{|l|}{ Time of the assault } \\
\hline During the night & 68 (51.9) \\
\hline During the day & 33 (25.2) \\
\hline Unspecified & 30 (22.9) \\
\hline \multicolumn{2}{|l|}{ Location of the assault } \\
\hline Victim's or rapist's home & $70(53.4)$ \\
\hline On the way & $38(29.0)$ \\
\hline In a taxi & $6(4.6)$ \\
\hline Workplace & $3(2.3)$ \\
\hline Unspecified & $14(10.7)$ \\
\hline \multicolumn{2}{|l|}{ Type of constraint } \\
\hline Physical & $73(55.8)$ \\
\hline Moral & $32(24.4)$ \\
\hline Armed & $19(14.5)$ \\
\hline Others & $7(5.3)$ \\
\hline \multicolumn{2}{|l|}{ Type of ingress } \\
\hline Vaginal only & $115(87.8)$ \\
\hline Anal only & $4(3.0)$ \\
\hline Both vaginal and anal & $12(9.2)$ \\
\hline \multicolumn{2}{|l|}{ Condom usage } \\
\hline Yes & $3(2.3)$ \\
\hline No & $128(97.7)$ \\
\hline \multicolumn{2}{|l|}{ Clinical lesions } \\
\hline Vulvo-vaginal lesions & $29(22.1)$ \\
\hline Vaginal lesions & $9(6.9)$ \\
\hline Vulvar lesions & $5(3.8)$ \\
\hline Anal lesions & $1(0.8)$ \\
\hline Others & $8(6.1)$ \\
\hline None & $79(60.3)$ \\
\hline
\end{tabular}


The aggressor was usually unknown (88/131; 67.2\%). When known, he had a family connection with the victim in most of the cases (26/43; 60.5\%). See Table 3.

Initial HIV testing was done in 80 patients $(80 / 131 ; 61.1 \%)$ and was positive in three (3/80; 3.8\%). Surgical repair of clinical lesions was needed in 17 cases (17/43; 39.5\%). Only 27.5\% (36/131) of the victims were prescribed an emergency contraception, while antiretroviral prophylaxis was done in 46.6\% (61/131) of them (Table 4).

\section{Discussion}

The majority of patients survivals of rape included in this series were infants or adolescents, more than one fifth being aged less than 10 years. This is similar to the findings of most of the authors [1]-[6], even those who included adults in their series [6]. In the largest sample of sexually abused victims recruited in Cameroonians secondary schools and published by Menick [3], $82.5 \%$ and $27.1 \%$ of the victims were respectively aged less than

Table 3. Relationship with the abuser $(n=131)$.

\begin{tabular}{cc}
\hline Relationship with the abuser & $\mathrm{n}(\%)$ \\
\hline Unknown & $88(67.2)$ \\
Family connection & $26(19.8)$ \\
Uncle & $14(10.7)$ \\
Cousin & $2(1.5)$ \\
Stepfather & $7(5.3)$ \\
In law & $3(2.3)$ \\
Friendship connection & $5(3.8)$ \\
Former sexual partner & $3(2.3)$ \\
Brother's friend & $2(1.5)$ \\
Neighboring & $8(6.1)$ \\
Professionals & $4(3.1)$ \\
Armed forces & $2(1.5)$ \\
Teacher & $2(1.5)$ \\
\hline
\end{tabular}

Table 4. Characteristics of the heath care for the victims of rape $(n=131)$.

\begin{tabular}{cc}
\hline Variable & $\mathrm{n}(\%)$ \\
HIV testing & $77(58.8)$ \\
Negative & $3(2.3)$ \\
Positive & $51(38.9)$ \\
None & \\
Treatment & $45(34.4)$ \\
Antiseptic washing & $17(13.0)$ \\
Surgical repair & \\
Prophylaxis & $51(38.9)$ \\
Antibioprophylaxis & $36(27.5)$ \\
Emergency contraception & $61(46.6)$ \\
Antiretroviral prophylaxis &
\end{tabular}


15 years and less than 10 years at the time of the assault. Also, Buambo-Bamanga et al. reported in Brazzaville that $46.1 \%$ of the cases of sexual abuse concerned adolescents aged from 10 to 14 years [6].

Single marital status, lack of regular income and a non university education level were found in most of the survival victims of rape in this study. This was not a surprising finding, as infancy and adolescence constituted the majority of the victims. Mbassa Menick et al. had similar results in a group of sexually abused females with psychiatric problems [7], as well as Parmar el al. who found a high prevalence of sexual violence among refugee population in Eastern Cameroon [8].

In our series, the aggression commonly took place during the night, at the victim's or the rapist's home, with physical constraint. These findings are similar to those of Menick et al. in a group of 269 Cameroonian students, who reported that $43 \%$ acts of sexual abuse occurred at the victim's home and $28.4 \%$ at the aggressor's home [3]. Also, $47 \%$ cases of sexual abuse in Brazzaville started with a physical constraint [6]. A high prevalence of physical constraint was also described by Traore et al. in Mali [9] as well as the high occurrence of rape during the night, which appear to be a common feature of rape worldwide [9]-[12].

As found in this study, a vaginal penetration without condom is almost the rule during rape [6] [9] [11] [12]. However, 16 of our victims (12.2\%) experienced an anal intromission. This type of ingress is less commonly reported in female victims of rape [6] [9] [11] [12] than it is in male victims and in marital sexual assault [13] [14].

Most of the lesions encountered in our series are vaginal and/or vulvar. Apart from La Harpe et al. who reported more body than genital lesions in rape victims in Geneva, our findings are similar to those of most authors who described lesions encountered following rape in female victims [1] [9] [12]. This is in conformity with the fact that the vaginal ingress is the commonest mode of penetration used by aggressors. Also, an important fraction of the rapists (24.4\%) have used non physical constraint in our series.

Contrary to the findings reported by many authors in Cameroon and worldwide [1] [3] [6] [9] [12], the assaulter was usually unknown in this series. However, Facuri et al. reported similar findings in Brazil [11]. When known, there was a family connection between the victim and the rapist in $60.5 \%$. This is a higher figure than the $31.4 \%$ cases of intra-familial rape reported by Menick et al. among 274 known Cameroonian rapists [3].

HIV testing was done in $61.1 \%$ of our rape victims and was positive in $3.8 \%$ of the tested subjects. This figure is close to the $2 \%$ of seroprevalence of HIV reported in victims of rape at Brazzavile [6]. The results of HIV testing three months after rape were not available in our series. Yet, Menick et al. have described a high rate of seroconversion of $37.5 \%$ among raped children in Cameroon [5]. At the same time, only $46.6 \%$ of our patients received an antiretroviral prophylaxis. This figure is low when compared, for example, to the Brazilian figures with a $90 \%$ of victims having preventive measures [11]. This is particularly alarming, especially as only one fifth of the victims of rape is known to consult a health care provider following rape occurrence in Cameroon [3].

Our results must be considered with the limitations inherent to retrospective studies, as the missing data can distort our figures. Because of missing data, nineteen cases of suspected rape could not be confirmed and were therefore excluded. This might give some bias to our results. Also, the psycho-social care of raped victims was not discussed in this study. In fact, because of limited human resources and competences in the study setting, this aspect is not routinely taken into account in the absence of obvious clinical manifestations.

\section{Conclusions}

Infancy and adolescence, unmarried status, low socioeconomic and education level are commonly found in raped victims in our setting. The assault usually takes place during the night, at home, with usage of physical constraint by an unknown aggressor and includes vaginal or/and anal ingress. The most encountered lesions are vulvar and vaginal, needing surgical repair in almost half of the cases.

There is a need to build comprehensive interventions in order to prevent rape and to reinforce the capacity of health care personnel for the management of raped cases in our setting. We also recommend further studies to address the issue of economic and psychosocial burden of the rape behavior in our setting.

\section{Declaration of Interest}

The authors report no declaration of interest.

\section{References}

[1] Koki Ndombo, P.O., Biyong, I.F., Eteki Tamba, N., Grüselle, G., Lantum, D. and Makang-Ma-Mbog, M. (1992) Child 
Victims of Sexual Abuse in Cameroon. Pediatric Annals, 39, 111-114.

[2] Menick, D.M. and Ngoh, F. (1998) Sexual Abuse in Children in Cameroon. Medecine Tropicale, 58, 249-252.

[3] Menick, D.M. (2002) Sexual Abuse at Schools in Cameroon: Results of a Survey-Action Program in Yaounde. Medecine Tropicale, 62, 58-62.

[4] Pitche, P. (2005) Child Sexual Abuse and Sexually Transmitted Infections in Sub-Saharan Africa. Medecine Tropicale, 65, 570-574.

[5] Menick, D.M. and Ngoh, F. (2003) Seroprevalence of HIV Infection in Sexually Abused Children in Cameroon. Medecine Tropicale, 63, 155-158.

[6] Buambo-Bamanga, S.F., Oyere-Moke, P., Gnekoumou, A.L., Nkihouabonga, G. and Ekoundzola, J.R. (2005) Sexual Abuse at Brazzaville. Santé, 15, 31-35.

[7] Mbassa Menick, D. and Ngoh, F. (1999) Reconciliation and/or Mediation Settlements in Cases of Sexual Abuse of Minors in Cameroon. Medecine Tropicale, 59, 161-164.

[8] Parmar, P., Agrawal, P., Greenough, P.G., Goyal, R. and Kayden, S. (2012) Sexual Violence among Host and Refugee Population in Djohong District, Eastern Cameroon. Global Public Health, 7, 974-994. http://dx.doi.org/10.1080/17441692.2012.688061

[9] Traore, Y., Mounkoro, N., Teguete, I., Djire, M.Y., Diallo, A., Bagayogo, M., et al. (2010) Clinical and Medico-Legal Aspects of Sexual Aggressions at Gabriel Toure Teaching Hospital. Mali Médical, 25, 27-30.

[10] Bartels, S.A., Scott, J.A., Mukwege, D., Lipton, R.I., Vanrooyen, M.J. and Leaning, J. (2006) Patterns of Sexual Violence in Eastern Democratic Republic of Congo: Reports from Survivors Presenting to Panzi Hospital in 2006. Conflict and Health, 4, 9. http://dx.doi.org/10.1186/1752-1505-4-9

[11] Facuri Cde, O., Fernandes, A.M., Oliveira, K.D., Andrade Tdos, S. and Azevedo, R.C. (2013) Sexual Violence: A Descriptive Study of Rape Victims and Care in a University Referral Center in São Paulo State, Brazil. Cad Saude Publica, 29, 889-898.

[12] La Harpe, R. and Vlastos, A.T. (2012) Sexual Assaults in Geneva between 2006 and 2010. Archiv für Kriminologie, 229, 117-125.

[13] Bullock, C.M. and Beckson, M. (2011) Male Victims of Sexual Assault: Phenomenology, Psychology, Physiology. Journal of the American Academy of Psychiatry and the Law, 39, 197-205.

[14] Mohammadkhani, P., Khooshabi, K.S., Forouzan, A.S., Azadmehr, H., Assari, S. and Lankarani, M.M. (2009) Associations between Coerced Anal Sex and Psychopathology, Marital Distress and Non-Sexual Violence. The Journal of Sexual Medicine, 6, 1938-1946. http://dx.doi.org/10.1111/j.1743-6109.2009.01273.x 